\title{
Saúde M ental na atenção básica à saúde de Campinas, SP: uma rede ou um emaranhado?
}

\author{
M ental health in the primary care system of Campinas, SP: \\ network or spider's web?
}

M ariana Dorsa Figueiredo ${ }^{1}$

Rosana Onocko Campos ${ }^{2}$

\footnotetext{
${ }^{1}$ Departamento deM edicina Preventiva e Social, FaculdadedeCiências M édicas, Universidade Estadual deCampinas. Cidade Universitária Zeferino Vaz, Caixa Postal 6111, Barão Geraldo. 13083-970, Campinas SP. madorsa@hotmail.com

${ }^{2}$ Departamento de

M edicina Preventiva e

Social, Faculdade de

Ciências M édicas,

Universidade Estadual de

Campinas.
}

Abstract This article relates a study on the organization of the mental health services in the primary care network of the city of Campinas (SP), beginning with the implantation of the management model called M atrix Support. This organizational arrangement is aimed at integrating primary and mental care by redirecting indiscriminate actions to the logic of co-responsibility in order to produce major effectiveness. Focal groups composed by mental health professionals from reference teams and managers were created. From the perspective of a hermeneutic-critical approach, we sought interrelating narrative argumentations with the construction of meanings. The incorporation of the mental health actions in the reference teams, as well as diversification of therapeutic measures was observed. We also evaluated the need to improve risk evaluation and to create permanent spaces for analyzing the potential of the M atrix Support to change hege monic practices. This article aims to contribute to the discussions about changes in the policies and care services in the field of mental health.

Key words Mental health, Collective health, Primary healthcare, $M$ atrix support, $M$ anagement
Resumo Trata-sedo relato deuma pesquisa sobrea organização das ações de saúde mental na atenção básica de Campinas (SP), a partir da implantação do arranjo de gestão Apoio M atricial. Esse arranjo visa a disparar a ampliação da clínica das equipes de referência e reorientar a demanda para a saúde mental. Desviando os encaminhamentos indiscriminados para uma lógica da co-responsabilização, ele pretende produzir maior resolutividade à atenção em saúde. Foram realizados grupos focais com profissionais de saúde mental, das equipes de referência e gestores. Numa abordagem hermenêuticacrítica, procurou-se encadear as linhas argumentativas dos grupos focais de modo narrativo, a fim de combinar a análise com a construção de sentidos para o material produzido. Observou-se a incorporação da saúde mental no fazer das equipes de referência e a diversificação dos dispositivos terapêuticos. Avaliou-se a necessidade de aprimorar a avaliação de risco e a importância da criação de espaços permanentes de análise sobre o A poio M atricial, a fim de realimentar sua potencialidade em transformar as práticas hegemônicas em saúde. Pretendese, com esteartigo, contribuir para que as discussões geradas pelos profissionais possam ser significadas no interior das transformações políticas e assistenciais na área da Saúde M ental.

Palavras-chave Saúdemental, Saúdecoletiva, Atenção básica à saúde, A poio matricial, Gestão 
Introdução

Esteartigo éresultante deuma pesquisa realizada na rede de atenção básica de Campinas (SP), que consistia em avaliar o funcionamento do arranjo organizacional Apoio M atricial daárea deSaúdeM ental, sob a ótica dos profissionais nele envolvidos.

Formulado por Campos $^{1}$ com o objetivo de aumentar o grau deresolutividade das ações de saúde, este arranjo provoca uma reformulação nos organogramas dos serviços, de forma que as áreas especializadas (outrora verticais) passam a ofere cer apoio técnico horizontal às equipesinterdisciplinares de atenção básica. A relação terapêutica, portanto, passaria a ser a linha reguladora do processo de trabalho, no qual as equipes de referência são as responsáveis por realizar o acompanhamento longitudinal do processo saúde/ doença/ intervenção de cada paciente. Desta forma, o Apoio M atricial seria uma ferramenta para agenciar a indispensável instrumentalização das equipes na ampliação da clínica², subvertendo o modelo médico dominante ${ }^{3}$, que se traduz na fragmentação do trabalho ena produção excessiva de encaminhamentos, muitas vezes desnecessários, às diversas especial idades ${ }^{1}$.

A experimentação deste arranjo foi inaugurada no município de Campinas (SP) a partir de 2001, com a implantação do Programa Paidéia Saúde da Família, uma adaptação do Programa de Saúde da Família do M inistério da Saúde, ajustado ao contexto sanitário local. Daí a escolha da rede de atenção básica destemunicípio como campo deinvestigação da pesquisa. No que se refere àárea de Saúde M ental, o município destaca-se no cenário nacional pela sua história de pioneirismo nos processos da Reforma Psiquiátrica. Sua rede de atenção básica conta com equipes de Saúde M ental desde a dé cada de $1970^{4}$, as quais foram marcadamente ampliadas durantea implantação do A poio M atricial ${ }^{5}$. Além disso, Campinas conta, atualmente, com um CAPSIII (Centro deAtenção Psicossocial com funcionamento 24 horas/dia eleitos deatenção à crise) para cada Distrito Sanitário, condição ainda rara nos diversos municípios brasileiros.

O Apoio Matricial: imbricando saúde e Saúde M ental

O A poio Matricial se configura como um suporte técnico especializado que é ofertado à uma equipe interdisciplinar desaúdea fim de ampliar seu campo de atuação e qualificar suas ações. Ele pode ser realizado por profissionais de diversas áreas especializadas, mas a pesquisa tomou como objeto de investigação a especificidade do Apoio Matricial da Saúde M ental, já que as questões subjetivas transpassam quaisquer problemas de saúde e devem ser abordadas em toda relação terapêutica.

Ainda, a atenção básica tem um importante papel na assistência a certas demandas em Saúde M ental. 0 M inistério da Saúde ${ }^{6}$ avalia que cerca de 9\% da população apresentam transtornos mentais leves e de 6 a $8 \%$ apresentam transtornos decorrentes do uso de álcool e outras drogas, pelos quais a atenção básica deve responsabilizar-se.

Uma pesquisa do M inistério da Saúde mostra que $56 \%$ das equipes de Saúde da Família referem realizar "alguma ação de Saúde M ental" ${ }^{6}$. Por sua proximidade com as famílias e as comunidades, essas equipes se constituem num recurso estratégico para o enfrentamento das diversas formas de sofrimento psíquico.

A Organização Mundial de Saúde e o Ministério da Saúde estimam que quase $80 \%$ dos usuários encaminhados aos profissionais de saúde mental não trazem, a priori, uma demanda específica que justifiquea necessidade deuma aten ção especializada ${ }^{5}$. Neste sentido, o A poio M atricial da Saúde $M$ ental seria potente para propiciar maior consistência às intervenções em saúdeem geral eem Saúde Mental em particular. A partir de discussões clínicas conjuntas com as equipes ou mesmo intervenções conjuntas concretas (consultas, visitas domiciliares, entre outras), os profissionais deSaúde $M$ ental podem contribuir para o aumento da capacidade resolutiva das equipes, qualificandoas para uma atenção ampliada em saúde que contemple a totalidade da vida dos sujeitos.

A responsabilização compartilhada pelos casos permiteregular o fluxo deusuáriosnosserviços. Através do Apoio M atricial, torna-se possível distinguir as situações individuaisesociais, comunsà vida cotidiana, quepodem ser acolhidas pela equipedereferência e por outros recursos sociais do entorno, daquelas demandas quenecessitam de atenção especializada da Saúde M ental, a ser oferecida na própria unidade ou, de acordo com o risco e a gravidade, pelo CAPS da região deabrangência. Com isso, épossível evitar práticas quelevam à "psiquiatrização" eà "medicalização" do sofrimento e, ao mesmo tempo, promover a eqüidadee o acesso, garantindo coeficientes terapêuticos deacordo com as vulnerabilidadesepotencialidades de cada usuário. Isso favorece a construção denovos dispositivos de atenção em resposta às diferentes necessidades dosusuários ea articulação entre os profissionais na elaboração de projetos terapêuticos pensados para cada situação singular.

Por ser 0 Apoio M atricial um arranjo inovador e recentemente implantado, é de grande impor- 
tância a formulação e 0 desenvolvimento de propostas de avaliação desta experiência, sobretudo porque, desde 2003, o M inistério da Saúde ${ }^{6}$ tem tomado este arranjo como estratégia para modular a inserção da Saúde M ental na atenção básica e aprimorar a rede de saúde dos municípios. A pesquisa, cujos resultados serão aqui apresentados, objetivou analisar o funcionamento do Apoio Matricial da Saúde M ental no Programa Paidéia Saúde da Família de Campinas (SP). Para tanto, tomou como objetivos específicos: a) investigar a articulação entre as equipes de Saúde M ental e as equipes de referência da atenção básica; b) investigar se a Saúde M ental tem de fato se constituído como rede de Apoio $M$ atricial para essas equipes, e c) analisar como e se a reorganização do processo de trabalho baseada no Apoio M atricial tem contribuído para a ampliação da clínica na rede de aten ção básica de Campinas (SP). Apresentaremos, a seguir, a contribuição desta pesquisa para fomentar o debate sobre esta e outras estratégias possíveis para integrar profissionais de saúde e especialistas em Saúde M ental no desenvolvimento de práticas menos fragmentadas e mais apropriadas ao contexto da atenção básica, capazes de sobrepor saúde e Saúde M ental como instâncias interligadas e complementares.

\section{Metodologia}

N uma abordagem hermenêutica, a pesquisa apoiou-se em alguns conceitos trabalhados por Gadamer ${ }^{7}$ para fundamentar o processo de investigação. Para este autor, o pesquisador é interpelado por questões não compreendidas a respeito de uma dada realidade, o que o faz voltar-se ao passado, à tradição, à historicidade dessas questões. No encontro produzido entre passado e presente, a fim de responder àquilo que 0 interpelou, o pesquisador opera o "destaque do objeto", de modo que o que será destacado como objeto de investigação, não será amputado de suas relações de produção, pois "[...] todo destacar algo torna simultaneamente visível aquilo do qual se destaca"7. No caso desta pesquisa, como o Apoio Matricial se destina a transformar práticas hegemônicas na saúde, a investigação esteve implicada com as tradições da área que comparecem ese atualizam nas práticas atuais.

Os efeitos da história no presente determinam o que se mostra como al go questionável e passível detransformar-senum objeto de investigação; portanto, a aplicação do conhecimento está colocada desde o início, pois éo próprio contexto da aplica- ção que faz possível o destaque do objeto. Ao analisar os entraves nos quais esbarra a implantação do Apoio M atricial em Campinas, pretendeu-selevantar proposições e buscar saídas para superar tais impasses. Ainda, a pesquisa teve a intenção de promover um espaço de análise para estimular a capacidade de intervenção dos participantes.

A pesquisa apoiou-setambém em Ricoeur ${ }^{8}$, que propõe conectar teoria crítica e hermenêutica. Se gundo este autor, à interrogação hermenêutica interessa o tipo de mundo que é aberto pelo texto, que é o que possibilita que a hermenêutica comporte uma crítica do real. 0 que produz o distanciamento necessário à compreensão éa fixação do discurso na escrita, o que possibilita que o texto se abra a su cessivas leituras situadas em diversos contextos socioculturais - nisso estaria a instância crítica da interpretação. 0 que deveser interpretado é a proposição de mundo contida no texto. Porém, ela "não se encontra atrás do texto, como uma espécie de intenção oculta, mas diante dele, como aquilo que a obra desvenda, descobre, revela"8.

A interpretação é aqui entendida como sendo composta pelos movimentos da análise e da construçãa ${ }^{9}$, com os quais se procurou agregar os fragmentos históricos e inerentes ao tema do Apoio $M$ atricial na produção de linhas de sentido. Essa construção de sentido se dá através do que Ricoeur ${ }^{10}$ chama agenciamento dos fatos, ou seja, da sua composição de modo narrativo. Fazer rupturas e religações, encadeando acontecimentos, histórias e linhas argumentativas, para depois reuniIos em uma narrativa. Uma narrativa que recupera a tradição para produzir um sentido novo e, ainda, necessário, já que se trata de histórias ainda não narradas e, por estarem inseridas no campo da práxis, "pedem para ser contadas"10.

\section{Os grupos focais \\ e a construção das diversas vozes}

O grupo focal éuma técnica quepossibilita uma análise em profundidade de dados obtidos numa situação de interação grupal. Ele permite verificar de que modo as pessoas avaliam uma experiência, como definem um problema e como suas opiniões, sentimentos e representações encontram-se associados a determinado fenômeno. Trata-se de desenvolver um processo que visa à compreensão das experiências dos participantes do grupo, do seu próprio ponto de vista. Além de possibilitar a apreensão não somente "do que" pensam os participantes, mas também "porque" eles pensam de determinada forma, essa interação grupal propor- 
ciona que o pesquisador possa observar como a controvérsia vem à tona e como os problemas são resolvidos ${ }^{11}$, evidenciando os diferentes graus de consensos e dissensos existentes. Essa técnica se mostrou apropriada aos propósitos da pesquisa, já que interessava analisar o posicionamento dos trabalhadores na constituição das equipes e a maneira pela qual isso se reflete na organização e no processo de trabalho.

A pesquisa se propôs a trabalhar com os principais agentes en volvidos na implantação e realização do Apoio M atricial, de modo a poder analisálo a partir de seus diferentes olhares. Foram definidos como grupos de interesse da pesquisa: profissionais de saúdemental (Unidades Básicas eCAPS), que realizam o Apoio $M$ atricial; profissionais de equipes de referência de Unidades Básicas que possuem equipes de Saúde M ental; profissionais de equipes de referência de unidades que não possuem equipes de Saúde M ental (essa distinção se deu porque nas unidades que não possuem equipes de saúde mental, o Apoio M atricial éfeito por profissionais de outras unidades ou do CAPS da região); gestores (coordenadora de Saúde M ental da Secretaria Municipal de Saúde, apoiadoras distritais e coordenadores de Unidades Básicas).

Foram feitos cinco grupos focais, nos quais participaram profissionais de todos os distritos de saúde de Campinas, representando cada um dos grupos de interesse. Eram duas as etapas para os grupos focais: a primeira tinhacomo objetivo construir, junto com os profissionais, um referencial teórico comum do Apoio Matricial, ou seja, um consenso sobre seus objetivos, meios e resultados pretendidos que pudesse servir como parâmetro para as reflexões sobre o cotidiano dos serviços e possibilitar a inclusão dos diferentes pontos de vista e suas diversas vozes. A segunda etapa seria 0 momento de analisar as vicissitudes da prática do A poio $M$ atricial, tendo o referencial teórico como pano de fundo.

Na primeira etapa para a construção do referencial teórico comum, foi feito um grupo focal misto, composto por representantes de cada um dos grupos de interesse. A composição mista deste grupo foi necessária para incluir, já desde o início do processo, as diferentes perspectivas na elaboração compartilhada do referencial teórico. $\mathrm{Na}$ segunda etapa, foram feitos quatro grupos focais, agora grupos homogêneos em relação aos grupos de interesse, ou seja, cada grupo focal era composto por profissionais de cada um dos quatro grupos de interesse. Foi privilegiada a homogeneidade dos grupos focais nesta etapa pois, segundo Westphal et al. ${ }^{11}$, os grupos mais homogêneos permi- tem obter resultados mais ricos e aprofundados sobre o tema, na medida em que cada grupo elabora e esmiúça as questões em discussão a partir de seu lugar específico enquanto componentes da trama social.

Em cada um desses quatro grupos, eram apresentados os principais tópicos que definiram o referencial teórico comum do A poio M atricial, para que este fosse validado. Depois de atingido um consenso possível, os profissionais eram convidados a falar livremente sobre suas experiências cotidianas no trabalho com o Apoio Matricial.

Interpretação:

a narrativa alinhavando sentidos

A pesquisa pretendeu trabalhar a interpretação em suas dimensões de análise e de construção. A análise seria a dimensão da fragmentação, o trabalho de esmiuçar os fenômenos para poder compreendê-los. E a construção, a dimensão fundamental para a elaboração de linhas de sentido que possam contribuir como saídas para os impasses encontrados.

Ricoeur ${ }^{8,10}$ destaca a necessidade de superar a separação existente entre o compreender eo explicar. A superação dessa dicotomia se buscaria, sobretudo, através do que 0 autor chama agenciamento dos fatos, ou a construção do sentido de modo narrativo. Para este autor, a narrativa como representação do tempo e da ação humana não se ordena necessariamente de forma cronológica, numa descrição linear dos eventos. Para representar a temporalidade da ação, a narrativa deve corresponder à experiência psicológica do tempo, sendo 0 encadeamento lógico dos fatos a sua característica fundamental. Ainda, 0 autor destaca que se uma ação pode ser narrada é porque ela já está inserida numa práxis social e por isso as narrativas seriam histórias não (ainda) narradas. "Narrar, seguir, compreender histórias é só a'continuação' dessas histórias não ditas"10. Ao utilizar a narrativa para interpretar o material produzido nos grupos focais, pretendeu-se fazer emergir, dos emaranhados das discussões, um sentido para as histórias vividas, mas ainda não narradas.

Assim, foi feita uma primeira interpretação das discussões dos grupos focais, considerando-a como uma unidade narrativa. As linhas argumentativas presentes nos diferentes discursos foram encadeadas uma a outra de forma que fosse construído o enredo próprio a cada grupo. A pós essas construções narrativas, foi feita uma segunda fase de interpretação confrontando as narrativas produzidas entre si: seus diálogos, convergências, di- 
ferenças e pontos de recalque. 0 produto dessa fase foi considerado como uma meta-narrativa, que pretendeu conectar os diferentes enredos e apostou, junto com Ricoeur, na tentativa de superar a dicotomia entre o compreender eo explicar.

Ainda, foi vinculado à meta-narrativa o contexto da produção histórico-social da saúde mental e da saúde coletiva, buscando identificar a presença de suas várias tradições que comparecem nos discursos e nas práticas e, além disso, foram propostas alternativas para o enfrentamento dos principais nós críticos encontrados, que podem servir para o aprimoramento da atenção em Saúde M ental esua efetiva inserção na rede básica de saúde. D essa maneira, procurou-se percorrer o círculo hermenêutico, passando várias vezes pelo mesmo lugar, porém sempre numa outra altitude. No dizer de Gadamer", "a compreensão não é nunca um comportamento somente reprodutivo, mas é, por sua vez, sempre produtivo. [...] quando se logra compreender, compreende-se de um modo diferente".

\section{Resultados: o quedizem os profissionais?}

A fim de sintetizar os resultados e sua posterior discussão, serão apresentados os principais achados em cada uma das narrativas construídas.

\section{Os profissionais de Saúde M ental}

Um dos aspectos marcantes na narrativa desse grupo foi a tendência em transferir, para as equipes de referência, a responsabilidade pelas dificuldades em realizar o Apoio $M$ atricial. Ou porque essas equipes teriam resistência em trabalhar com o que não é medicamentoso ou porque representam o Apoio como uma imposição da gestão. Há pouco reconhecimento sobre sua própria dificuldade de compreender a proposta, assumir o papel de apoiadores e compartilhar seu saber.

Segundo este grupo, a maior parte da demanda em Saúde M ental são casos considerados leves. Assim, avaliam que o Apoio M atricial pode ajudar a aumentar a capacidade resolutiva das equipes de referência, para que os profissionais de Saúde M ental possam abrir sua agenda para os casos graves. Para isso, consideram necessário adequar a clínica da Saúde M ental às necessidades da população edo contexto da saúde coletiva "centrar em intervenções mais breves, fazer grupos de duração limitada". Listam recursos a serem usados como alternativas à assistência tradicional da saúde mental, no sentido da ampliação da clínica tanto das equipes de referência quanto da própria saúde mental. "grupo de convivência para mulheres", "espaço cultural, oficinas", "Lian Gun [atividade física de origem oriental]; ginástica postural, brinquedoteca". Porém, acham que é preciso também garantir as ofertas tradicionais da saúde mental para os casos mais graves: "existe um grupo de pessoas que têm um sofrimento que vai um pouco além de só trabalhar nesses grupos, que precisa mesmo de psicoterapia, 0 atendimento com o psiquiatra pra medicar".

Foi salientada a capacitação in loco que o A poio $M$ atricial proporciona, quese daria através de atendimentos conjuntos entre o profissional da Saúde $M$ ental e o profissional de referência. Com isso o profissional de referência pode aprender na prática como avaliar e intervir em Saúde M ental. Esses atendimentos teriam duração temporária, com a intenção que o profissional de referência passe a intervir sozinho.

0 grupo destaca o problema da definição de responsabilidades e, com isso, os vários encaminhamentos gerados. "Eu digo a eles que eles podem dar conta e eles teimam que a genteéquetem que atender", "E volta pro generalista, volta pro psicólogo". Neste sentido, consideram o Apoio $M$ atricial como forma de compartilhar responsabilidades. Ele exige que os profissionais, juntos, compreendam o caso e suas necessidades, e só então seria possível bloquear encaminhamentos indiscriminados e decidir sobre responsabilidades de cada profissional.

As equipes de referência de unidades que possuem equipes de Saúde M ental

Para esse grupo, a capacidade da equipe de referência em acolher o sofrimento depende da disponibilidade do profissional, do seu perfil e da sua formação. Foi marcante nesta narrativa a expressão da angústia ao entrar em contato com o sofrimento, e também um certo medo em relação à necessidade de lidar com os pacientes considerados da Saúde Mental. Avaliam que sua formação não contribui para que possam intervir no campo da Saúde M ental.

Segundo o grupo, é possível acolher e orientar os pacientes na perspectiva da clínica ampliada, mas se preocupam com a eficácia de suas intervenções, no sentido de que produziriam resultados apenas imediatos: "Ela ficou bem naquelemomento, mas e depois de sair de lá?" Se remetem ao receio de não serem capazes de fazer uma avaliação adequada: "N ão vou conseguir dizer seela tem saúde mental ou não e se éum transtorno permanente", "Naquele momento ela tá bem, e depois faz uma besteira na casa dela". 
Consideram que a ampliação da capacidade resolutiva das equipes de referência, em alguns casos, não pode substituir as ofertas especializadas da SaúdeM ental, as quais são insuficientes frenteà grande demanda: "As equipes de referência podem estar trabalhando num campo grande, só que tem um núcleo que precisa do psiquiatra, da psicóloga, da TO, e não tem".

Sal vo essas situações mais graves, acreditam que a equipe de referência deva intervir, tentan do superar as dificuldades. Entendem que o contexto social e a forma com que as pessoas lidam com a vida são fatores queinfluenciam em sua saúde mental. "Saúde mental acho que tá relacionado com a autonomia, né, de lidar com os problemas da vida, de se sustentar, de trabalhar, se relacionar com as pessoas". Haveria outros recursos a serem usados pela própria equipe der eferência no Centro deSaúdeou na comunidade: "Grupos de qualidade de vida, artesanato, fuxico, pintura, grupos de dança, coral".

O grupo identifica o Apoio M atricial como uma forma de capacitação e valoriza a estratégia criada para orientar os atendimentos: "A gentefoi estabelecendo roteiros, o que fazer quando, de como abordar, de como fazer uma escuta mental, de que dados são importantes pra gente levar pra reunião de matriciamento".

As equipes de referência que não possuem equipes de Saúde M ental em suas unidades

Estegrupo elabora uma diferença entreo "apoio que dá certo" e o "apoio que não dá". 0 "apoio que dá certo" seria aquele em que o apoiador absorveo caso para si, ou seja, a equipe de referência consegue encaminhar o caso. 0 "apoio não dá certo", quando 0 apoiador se coloca para ajudar a equipe a acompanhar o caso. Segundo o grupo, como os profissionais de saúde mental não estão sediados em suas unidades, o fluxo de encaminhamentos não é automático. Por isso, o grupo refere quetem que assumir a maior parte da demanda, só acionando o A poio $M$ atricial para os casos que têm extrema necessidade de atendimento da Saúde M ental. Assim, justificam que a resposta esperada do Apoio M atricial seja, sobretudo, o encaminhamento para atendimento especializado. Quando essa resposta não acontece e o que se propõe no matriciamento é uma discussão do caso para que a equipe possa acompanhá-lo, o grupo considera que a assistência fica prejudicada: "Chega até no A poio M atricial, mas depois daí pára, não vai nem pro CAPS e nem tem uma resposta concreta".

O grupo discute a saúde mental como qualidade de vida, sendo influenciada pelas condições so- ciais das pessoas, e acredita que a própria equipe de referência pode oferecer recursos terapêuticos, além da assistência direta da Saúde M ental. Este grupo, assim como o grupo anterior, também vê nos roteiros criados para orientar os atendimentos uma forma eficaz de capacitação.

\section{Os gestores}

Os gestores avaliam que as equipes de referência modificaram a maneira delidar com a subjetividade. Isso provocou um redirecionamento de fluxo para a Saúde M ental, o que facilita o acesso dos usuários com demandas que antes eram atribuídas à Saúde M ental. As questões que atualmente são levadas para o A poio Matricial são questões mais complexas. Este grupo destaca a função pedagógica do apoiador matricial, principalmentenosatendimentos conjuntos com o profissional de referência.

A insuficiência de profissionais em relação à demanda é vista pelos gestores como uma dificuldadeque, ao mesmo tempo, se tornou um estímulo para que as equipes de referência buscassem alternativas, tencionando assim a responsabilização.

Eles consideram que a atenção básica deve desenvolver o trabalho preventivo e educativo. No entanto, também deve ofertar propostas clínicas e curativas, nucleares da Saúde M ental, porém acreditam que é preciso ainda avançar no desenvolvimento de propostas mais adequadas e menos medicalizantes para o contexto da atenção básica.

Avaliam que, apesar do processo de discussão que fizeram para disparar a implantação do Programa Paidéia, poderiam ter investido numa discussão específica sobre o Apoio Matricial, o que contribuiria para uma melhor compreensão da lógica de funcionamento deste arranjo.

\section{Discussão}

Se uma primeira intenção do A poio $M$ atricial era fazer com que a Saúde M ental saísse do núcleo especializado para transitar no fazer das equipes, é possível considerar que houve uma propagação nesse sentido. Os diferentes grupos afirmam que há um engajamento nas discussões de caso, tanto por parte dos profissionais de Saúde M ental como das equipes de referência, as quais têm se dado a considerar a Saúde M ental de uma forma menos compartimentalizada.

Em todos os grupos, foi discutida a necessidade de romper com a superespecialização da área da saúde e a pertinência da supressão da lógica tradicional do encaminhamento, principalmenteno 
contexto da atenção básica. Os grupos indicam mudanças em relação ao modo de trabalho anterior ao Apoio M atricial; em todos eles, foram feitas referências ao abandono de uma conduta antes em voga nas U nidades Básicas, evidente na fórmula "ao paciente que chora, um encaminhamento para a psicologia". De certa forma, a lógica da coresponsabilização vem sendo tencionada a se sobrepor à lógica do encaminhamento, o quefaz com que 0 sofrimento psíquico deixe de ser responsabilidade exclusiva da Saúde M ental.

Os grupos reconhecem que onde se conseguiu instituir o A poio M atricial, e apesar das adversidades, a ampliação da clínica vem sendo conquistada, tanto no que diz respeito ao acolhimento da dimensão da subjetividade pelas equipes de referência, quanto na diversificação das ofertas terapêuticas da Saúde M ental, que vem extrapolando a sua atuação dos consultórios para o território. Outro ganho trazido pelo Apoio Matricial é a modificação do foco da orientação da assistência, quese desloca progressivamente dos serviços eseus cardápios de programas e ofertas, para se dar a partir das necessidades dos sujeitos, das famílias, do território e da rede de relações que nele acontecem. A construção de projetos terapêuticos pensados para cada situação singular, princípio herdado da Reforma Psi quiátrica e carro-chefe da assistência nos CAPS, ganha lugar no fazer dos diversos profissionais da aten ção básica.

Todas essas conquistas não significam, evidentemente, quea subversão da lógica detrabalho buscada pelo A poio M atricial esteja resolvida, atéporque o que se observa é mais uma sobreposição de duas lógicas antagônicas e menos a substituição de uma pela outra. Houve, de fato, o desencadeamento de um processo em que os encaminhamentos deixam de ser automáticos para poderem ser discutidos em equipe, mas nesse processo incidem inúmeras variáveis, fazendo com que ora predomine a fragmentação, ora se evidencie a co-responsabilização.

Da perspectiva dos profissionais de Saúde M ental, as equipes de referência costumam evitar o contato com o sofrimento psíquico a partir de justificativas como a insegurança gerada pela falta de formação em Saúde M ental e a dificuldade em intervir fora do campo mais objetivo dos procedimentos e da conduta medicamentosa.

As equipes de referência, por sua vez, admitem o aumento da resolutividade quando ampliam seu campo de intervenção para além dos aspectos biológicos, mas consideram sua formação inadequada para compreender elidar com a subjetividadee o sofrimento psíquico. Aliada à angústia gerada no contato com o sofrimento, a formação dita ina- dequada aparece como justificativa para os encaminhamentos. No entanto, valorizam o incremento de sua formação a partir das discussões queo apoiador vem desencadear e, a partir disso, consideram possível pensar e transformar sua prática, fazendo surgir alternativas criativas e mobilizadoras para os serviços.

A função pedagógica do A poio M atricial ébastante enfatizada nas narrativas da Saúde M ental e dos gestores, os quais destacam a capacitação in loco como fundamental para que as equipes de re ferência aprendam, durante a prática, a intervir no campo da subjetividade. Porém, essa forma de capacitação não é lembrada pelas equipes de referência como um dispositivo deaprendizagem. São mais valorizados os roteiros criados para aprimorar a coleta de informações e orientar os atendimentos, talvez por aludirem aos clássicos protocolos, uma ferramenta de gestão e direcionamento da clínica difundida pela Programação em Saúde. Tais roteiros amparam as equipes nas intervenções, mas por serem bastante prescritivos, é preciso cuidar para que não se transformem em scripts estanques que podem provocar trabalho alienado e burocratizar os atendimentos. Consideramos que seja importantevinculá- los a uma constante avaliação do processo de trabalho e a um maior investimento nos atendimentos conjuntos com o profissional "psi", pois o processo de ensino-aprendizagem in loco é uma estratégia bastante adequada para que os profissionais possam se autorizar nas intervenções que nem sempre cabem nas balizas dos protocolos.

Ao analisarmos a concepção de saúde mental subjacente nas falas dos diferentes profissionais, observamos um significativo consenso no que se refere às determinações do processo saúde-doença. Os profissionais de Saúde M ental discutem a saúde mental como fortemente influenciada por fatores sociais, pela capacidade dos sujeitos de lidarem com os problemas advindos de seu contexto de vida e pelo grau de participação social, expresso tanto nos vínculos afetivos e de convivência com seus pares quanto no exercício da cidadania. M arcas da tradição basagliana da Itália, aparecem aqui a autonomia, a convivência ea cidadania como princípios da reabilitação psicossocial buscados pela R eforma Psiquiátrica brasileira e que ganham ressonância na aten ção básica, para além dos CAPS como dispositivos básicos da reforma. Esses princípios também se manifestam nas falas dos profissionais das equipes de referência, e podemos considerar que a aproximação desses profissionais à essa discussão se deve pelo movimento gerado com o A poio M atricial ao deslocar a Saúde M ental para as trocas no coletivo das equipes. 
Dessa concepção mais ampliada de saúde mental, desenvolvem-se al gumas propostas assistenciais ao estilo da reabilitação, que se fundamentam na importância do incremento dos laços sociais e no aumento do grau de autonomia e contratualidade das pessoas. São os grupos de produção de saúde com modalidades diversas, como os grupos de convivência, artesanato, etc., os quais, de outro lado, são também resgatados da tradição da promoção à saúde, que historicamente vem privilegiando as propostas grupais como recursos estraté gicos para a atenção e focados no desenvolvimento de medidas de autocuidado e na melhora da qualidade de vida.

Através desses dispositivos, se podem atingir resultados substantivos na construção de sentido aos projetos de vida de sujeitos que experimentam a exclusão social, o isolamento afetivo, a impossibilidade de desempenhar protagonismos. $\mathrm{Não}$ obstante, é preciso destacar que, muitas vezes, tais grupos são utilizados nem tanto em função de sua potencial idadeinerente, mas são empregados como subterfúgio para a atenção à grande demanda. Nisso, encontramos a herança do "eficientismo" da Saúde Pública, na premissa do produzir mais no menor período de tempo possível, que nem sempre caminha ao lado da resolutividade da assistência em saúde. Tampouco podem a pintura, 0 artesanato, a caminhada serem tomados como fins em si, pois que eles são instrumentos por meio dos quais se irão buscar a produção de novos sentidos na história dos pacientes. Não bastaria diversificar a oferta de dispositivos de atenção em Saúde M ental sem que isso venha combinado a uma robusta discussão sobre o modelo clínico que fomenta essas propostas e com a radicalidade de sua incorporação pelos profissionais que as conduzem. Entendemos, ainda, que a diversificação dos dispositivos terapêuticos não deva prescindir às técnicas tradicionais da Saúde M ental, como a psicoterapia e a medicação psicotrópica, sem dúvida apropriadas em inúmeros casos, mas que devem ser empregadas, sempree como em qualquer oferta, com base na singularidade das demandas.

Em relação à capacidade resolutiva das equipes, encontramos uma diferença acentuada entre as equipes de referência de Unidades Básicas onde estão sediados os profissionais de Saúde M ental e as equipes de referência de Unidades que recebem Apoio Matricial de outros serviços. As primeiras têm maior dificuldade em modificar a maneira automática de encaminhar os pacientes, pelo acesso mais facilitado aos profissionais, corroborado pela força do modelo instituído. É na narrativa dessas equipes que fica marcante a angústia que sentem os profissionais ao entrarem em contato com o sofrimento psíquico, tal vez pelo costume de del egar à Saúde M ental a responsabilidade por essa demanda. Já na narrativa das equipes de unidades que não possuem equipes de Saúde M ental aparecem al guns critérios mais apurados que norteiam a avaliação de risco, assim como uma referência à sua maior autonomia no acompanhamento de pacientes em sofrimento psíquico. Coincidindo com as falas dos profissionais de Saúde M ental que as apóiam, essas equipes costumam acionar 0 Apoio M atricial após já terem esgotado a discussão do caso e avaliado a legítima necessidade de atendimento especializado.

Essa diferença nos chama a pensar sobre a inserção da assistência em Saúde M ental nas Unidades Básicas. Descentralizar a Saúde M ental para os territórios foi uma conquista cara à Reforma Psiquiátrica econsideramos necessário aprimorar esse modelo, vinculando cada vez maisa assistência com a análise e utilização do território e da rede social, a fim de desenvolver uma clínica implicada com a constituição de sujeitos mais saudáveis em sua afetividade e em suas relações sociais, e mais potentes para transformar a realidade. Ainda, consideramos essa tensão estabelecida entre os profissionais de Saúde M ental eas equipes de referência como uma força sau dável, capaz de desestabilizar o instituído e pôr a prática em movimento em torno das reflexões nascidas da fertilidade desse encontro.

Esse ponto de tensão situa-se onde o Apoio $M$ atricial provoca e explicita uma intensa imprecisão das fronteiras entre o que é de responsabilidade dequem. Q uando setrata de pacientes queapresentam transtornos psíquicos mais graves, não há desacordo sobre a necessidade da intervenção e do núcleo da Saúde M ental. M as arma-se uma grande peleja quando o que está em jogo são questões subjetivas que não se encaixam na rigidez dos diagnósticos, como as dificuldades afetivas e relacionais, a capacidade maior ou menor de enfrentar os problemas cotidianos ou outras necessidades que demandam orientação e escuta acolhedora. Nesses casos, a potência do A poio M atricial está justamente em desfazer a delimitação entre as diferentes disciplinas e tecnologias, e, através das discussões de caso e da regulação de fluxo, reverter 0 processo de "psicologização" do sofrimento.

A respeito da regulação defluxo, devemos pensar sobre uma questão que surge a partir das narrativas: até que ponto as equipes de referência podem intervir? A angústia e a insegurança trazidas pelos profissionais podem ser lidas como sendo próprias ao trabalho em contato com o sofrimento, mas também expressam certa desproteção des- 
ses profissionais pela falta de recursos teóricos e técnicos para a ação. Muitos profissionais afirmam que podem acolher os pacientes e escutá-los em seu choro, mas para além do acolher, não sabem como fazer uma interven ção que seja potente como resposta àquele choro. Acreditamos ser importante diferenciar a capacidade que todo profissional de saúde deveter para uma prática integral ehumanizada, daquilo que extrapola sua formação no que se refere à compreensão dos processos psíquicos e aos modos de intervir nucleares da Saúde M ental. Ou, no limite, se correria o risco de diluir a especificidade e a relevância dos saberes e tecnologias da área "psi", negligenciando a assistência às pessoas que demandam o núcleo especializado. É necessário investir num debate mais aprofundado sobre critérios de risco em Saúde M ental, a fim de viabilizar uma avaliação mais apurada sobre as vulnerabilidades e potencial idades de cada paciente. Uma avaliação feita com qualidade possibilitará fazer uma melhor distinção de quais pacientes as equipes de referência têm competência para acompanhar de forma resolutiva e responsável.

Entendemos que, assim como em qualquer processo de mudança institucional, outra dificuldade na implantação do Apoio M atricial situa-se no descompasso entre os tempos e ritmos da gestão, e o ritmo das transformações das práticas no cotidiano, ditados e expressos pelo sentido que os profissionais imprimem às diretrizes. Os gestores avaliam quea implantação do modelo Paidéia precisou se dar com radicalidade para tornar possível a mudança de cultura pretendida, e reconhecem que isso se traduziu na maneira pouco processual com que foram introduzidas as transformações nos serviços. Como conseqüência disso, há uma avaliação de que o Apoio M atricial foi sentido como uma imposição da gestão e, sem poder compreender suas finalidades, alguns profissionais permaneceram pouco permeáveis às mudanças. Porém, em todas as narrativas se evidenciou a importância do papel do gestor local e do apoiador distrital. Em seu lugar de mediação entre as propostas de governo e as práticas dos profissionais, esses gestores devem fortalecer a incorporação das diretrizes e oferecer escuta e suporte para as questões trazidas pelos profissionais, tentando continuamente negociar contratos e compromissos para instituir a nova lógica de trabal ho.

Embora os gestores ponderem que houvegrande investimento nas negociações com os profissionais durante a implementação das diretrizes, não houve discussões específicas para pensar o projeto instituinte do A poio M atricial, a fim de que a mudança pudesse de fato fazer sentido aos profissionais. Devemos reconhecer que a mudança da lógica de trabalho proposta pelo A poio M atricial não é fácil de ser assumida pelas equipes e não ocorre automaticamente. Ela deveser especificamentetrabalhada junto às equipes, instalando-se espaços destinados à reflexão eà análise crítica sobreo próprio trabalho, e que possam ser continentes aos problemas na relação entre a equipe, aos preconceitos em relação à loucura, à dificuldade deentrar em contato com o sofrimento do outro e à sobrecarga trazida pela lida diária com a pobreza e a violência. Todas essas questões podem se colocar como possíveis entraves para a realização do A poio $M$ atricial, se os profissionais não tiverem espaços de reflexão e formação permanentes para processá-las, que sejam capazes de realimentar constantemente a potencialidade do Apoio M atricial enquanto arranjo transformador das práticas hegemônicas na saúde.

\section{Colaboradores}

M D Figueiredo e R Onocko Campos participaram igualmente de todas as etapas da elaboração do artigo. 


\section{Referências}

1. Campos GWS. Equipes de referência e apoio especializado matricial: um ensaio sobre a reorganização do trabalho em saúde. Cien Saude Colet 1999; 4(2):393-403.

2. Campos GWS. A clínica do sujeito: por uma clínica reformulada e ampliada. In: Campos GWS. Saúde Paidéia. São Paulo: Hucitec; 2003. p.51-67.

3. Onocko Campos R. A gestão: espaço de intervenção, análise e especificidades técnicas. In: Campos GWS. Saúde Paidéia. São Paulo: Hucitec; 2003. p.122-149.

4. Campos FCB. 0 modelo da reforma psiquiátrica brasileira e as modelagens de São Paulo, Campinas e Santos [tese]. Campinas: Departamento de Medicina Preventiva e Social/ FCM/ UNICAMP; 2000.

5. Campinas. Secretaria M unicipal de Saúde. Projeto Paidéia Saúde da Família. 2001. [acessado 2007 jul 29]. Disponível em: http://www.campinas.sp.gov.br/saude/programas/protocolos/protocolos_mental

6. Brasil. M inistério da Saúde. Coordenação de Saúde M ental/Coordenação de Gestão da Atenção Básica. Saúde mental e Atenção Básica: 0 vínculo e o diálogo necessários. Braślia: M inistério da Saúde; 2003. [Mimeo].

7. Gadamer HG. Verdade e método: traços fundamentais de uma hermenêutica filosófica. Petrópolis: Vozes; 1997.

8. Ricoeur P. Interpretação e ideologias. Rio de Janeiro: Francisco Alves Editora; 1990.

9. Onocko Campos R. O encontro trabalhador - usuário na atenção à saúde: uma contribuição da narrativa psicanalítica ao tema do sujeito na saúde coletiva. Cien Saude Colet 2005; 10(3):573-583.

10. Ricoeur P. Tempo e narrativa. Tomo I. Campinas: Papirus; 1997.

11. Westphal MF, Bógus CM, Faria MM. Grupos focais: experiências precursoras em programas educativos em saúde no Brasil. Boletim da Oficina Sanitária do Panamá 1996; 120(6):472-482.

Artigo apresentado em 02/08/2007

Aprovado em 13/12/2007 